\title{
Influence of Socio-Economic Factors on Choice of Childbirth Place Among Women In Oyigbo L.G.A., Rivers State, Nigeria
}

\section{Ngozi Afulenu Obika-Ndiri}

African Centre of Excellence for Public and Toxicology Research (ACE-PUTOR), University of

Portharcourt

\section{Chizoma Millicent Ndikom}

University of Ibadan College of Medicine

Ogochukwu Immaculate Obika ( $\square$ obika.immaculate@gmail.com )

University of Lagos College of Medicine https://orcid.org/0000-0002-2571-8479

\section{Research}

Keywords: Maternal and child health, Maternal Mortality and morbidity, Delivery, Obstetric, Midwifery, Home birth, Health Facilities/Hospitals, Traditional birth attendants, Oyigbo, Nigeria

Posted Date: November 15th, 2021

DOI: https://doi.org/10.21203/rs.3.rs-1039082/v1

License: (c) (i) This work is licensed under a Creative Commons Attribution 4.0 International License. Read Full License

Version of Record: A version of this preprint was published at Journal of Midwifery on December 27th, 2022. See the published version at https://doi.org/10.25077/jom.7.2.66-76.2022. 


\section{Abstract}

BACKGROUND: Choices of childbirth places among women may influence the rate of maternal risks and some social and economic factors which encourage maternal mortality are still a major challenge especially in developing countries like Nigeria, one of the commonest of these childbirth place choices is home birth. The aim of this study was to find out the prevalent socio-economic factors that influence the choice of childbirth places among the women of child bearing age in Oyigbo Local Government area of Rivers State in Nigeria.

METHODOLOGY: A self-structured questionnaire was used as instrument to collect data for the study through simple random sampling, and these data was analyzed using Frequency and percentage for descriptive statistics while chi-square was used for inferential statistics at 0.05 level of significance.

RESULT: The result showed that mean age of the women is 35.27 and most of them had secondary education, also there was a high level of hospital/health facility adherence among the women in Oyigbo Local Government Area of Rivers State and there were no significant association between social factors and choices of childbirth places among the women, and also there was significant associations between income and choices of childbirth places among the women but there were no significant association between the educational qualifications and choices of childbirth places among the women.

CONCLUSION: There is a slight influence of social factors on the choices women make on childbirth places, since maternal health and antenatal knowledge is now easily accessible to everyone even without formal education, however, the cost implication of delivery in health facility and economic empowerment of women should be considered, therefore this study has shown that the choice of childbirth place is majorly influenced by their level of income.

\section{Introduction}

\subsection{Maternal mortality}

This refers to any loss of a woman's life resulting from pregnancy complication or death within 42 days after childbirth, notwithstanding the period or site of the pregnancy, emanating from issues that are linked or escalated by the management of the pregnancy but not from accident or incidental factors [1]. There are other known factors aside medical conditions responsible for maternal mortality in Nigeria-these factors include but are not limited to social, economic and cultural factors, which have a direct influence on maternal mortality [1]. Women die during childbirth due to complications such as unsafe abortions, infections after childbirth, pre-eclampsia or eclampsia, complications during labour and after delivery [2]. Another study based on a reports include haemorrhage, abortion, hypertensive disorders of pregnancy, sepsis and obstructed labour as the major causes of maternal deaths. It also lists major infectious diseases, such as malaria and viral hepatitis, as well as non-infectious conditions like anaemia [3]. Healthcare workers need to provide a more supportive environment by being sensitive and accommodating to diverse socio-cultural perspectives and employing tact in educating women or 
managing their needs [3]. Maternal mortality has become a serious problem in middle income countries with Sub-Saharan African amounting for $56 \%$ of the maternal deaths [2].

\subsection{Maternal morbidity}

This refers to the disease/illness experienced by pregnant women. Many times, this often results in an inability to function properly and in many situations affects the 'victim's economic, social and fertility roles [1]. Maternal morbidity could become chronic in a mother during and after pregnancy. Chronic morbidities are not life-threatening but could affect the women's functionality such as uterine prolapase, fistula and other minor conditions like hernia, post partum depression, urinary incontinence, hemorrhoids etc [4]. The medical causes of maternal mortality are also important for morbidity diagnosis and to the list of the factors are added anaemia and depression [5].

\subsection{Maternal health care}

This is the overall wellbeing of women at the stage of pregnancy and children below age 5. Maternal healthcare is a comprehensive care to mother and child as it includes educational, social, nutritional services as well as medical care during pregnancy, labour and post pregnancy. As has been observed, some reasons have been attributed to why many pregnant and nursing mothers chose not to make use of appropriate antenatal and postnatal cares are due to poverty, distance to the health facility, low educational status, lack of awareness of services available to them, cultural beliefs and religious practices [6]. It is important that all childbirths are attended to by skilled health professional to ensure early care and treatment thereby reducing the death of mother and baby [2]. Also discriminatory attitude based on religious factor affects the maternal health care of women from different backgrounds [7]. To improve maternal health, issues of inequalities that affect the outcome of a maternal health especially on rights, gender, reproductive health care such as family planning and access to respectful and high quality maternity care [8].

\subsection{Socio-economic factors influencing child birth places}

Various social groups in Sub-Saharan Africa practice different lifestyles, which may differ in some aspects but are almost similar in contexts [9]. Studies have shown that maternal procedures in SubSaharan Africa are prone to crisis as a result of multiple social and economic factors. These social factors affect the child practices among women of child bearing age in most countries in these parts of Africa [10]. Social factors are experiences which influence the way an individual thinks, lifestyle and attitude. The common social factors which have affected childbirth include: educational background, accessibility to good medical care and child birth facilities, environmental and climate of the individuals' residence, societal/personal lifestyle adopted by individuals etc.

Nigeria consists of numerous social groups and each of these groups has their own common interests guided by lots of factors. The social factors that commonly influence childbirth practices in Nigeria are associated with increased maternal or pre-natal morbidity [9]. One of the commonest childbirth practices that can be associated with social factors among Nigerian women is the practice of home births. 
In Madagali which is located in North-Eastern Nigeria, a significant number of home births take place and are supervised by unskilled individuals. These home births account for high mortality rate in the Northern part of the country [11]. In addition to home births, women in this part of the country face poor education and low socio-economic status in their societies. Because of this, lack of proper education has led these women to believe that home birth is safer for them. Also, these women participate mainly in house chores, farming and petty trades. Hence, they do not have the financial capabilities to pay for hospital births under the supervision of skilled personnel [6]. This has led many of them to settle for home births.

The marital status of the women of childbearing age in Sub-Saharan Africa is another significant social factor that influences their child birth practices and the delivery places they may choose. For instance, single or divorced women may be able to make decisions by themselves, without any man (husband) influencing their decisions on their choice of birth methods, as compared to married women [12].

Another social factor which influences child birth in Sub-Saharan countries like Nigeria, Niger and Benin Republic is that women are exposed to childbirth within short intervals, due to their societal demands to satisfy the quests of the men to have large family size [13]. Many women now conceive and give birth to numerous children within short intervals. This has lead to an increase in infant morbidity and mortality in these regions [9]. In Lagos State, Nigeria, the childbearing women of Ogu speaking people of Badagry often give birth to children within short intervals [14]. This implies that men play a huge role to the conditions of the pregnant women in the community. This is perceived as a means of satisfying their husbands' quest for large family size, which may not be unconnected with the effect of decision making in the family.

The study by Ezeama \& Ezeamah suggested that malnutrition is another social factor influencing the childbirth practices among the women; the findings from this study showed that some pregnant women are malnourished by their diets because they eat only what are obtainable in their community [12]. This can also be associated with lack of education regarding antenatal and maternal care. If these women are exposed to enlightenment from skilled professionals, they would be able to take food that would improve their conditions during pregnancy and child delivery.

In the Southern part of the country, the lifestyles of the individuals also influence childbirth practices. For instance, the residents of riverine areas of Bayelsa and some parts of Rivers state, practice home births because they have adopted it as their lifestyle. It is easier to deliver at home than cross the river on a boat during labor to a nearby hospital in such environments [15].

One of the major causes of maternal mortality among women of child bearing age is the lack of adequate access to skilled personnel [16]. In Sub-Saharan African, many women do not have access to skilled personnel during childbirth [17]. Globally, existing literature points to various social and economic factors that have been attributed to low access to health facilities and skilled personnel [18] by expectant women. In Ethiopia, although there has been tremendous improvement in terms of providing adequate maternal healthcare, maternal mortality is recorded to be among the highest in the world with 412 deaths per 100,000 live births [19]. The study by Bukar and Jauro, has also shown that in low-income countries, 
the major cause of maternal mortality is unskilled birth attendance [11]. It is necessary to improve skilled care at birth in order to reduce maternal death. Records have shown that a $10 \%$ increase in skilled birth attendance corresponds to $5 \%$ reduction in maternal deaths [20]. Studies have shown that maternal procedures in Sub-Saharan Africa are prone to crisis as a result of multiple social and economic factors. These social factors such as occupation and education affect the child practices among women of child bearing age in most countries in these parts of Africa [10].

The effects of education are assumed to predominantly flow through women's cognitive skills, material resources, and autonomy, which should in turn affect their maternal practices and healthcare use, and ultimately their health outcomes [21]. Education should have a positive effect on women's cognitive skills especially literacy, should benefit maternal health by increasing women's ability to seek information about their own health and by assuring that women are better able to follow written instructions. Education reduces the effect of patriarchal system; men have traditionally been the economic providers for their families and the ones to determine how household resources are spent, However, if education increases women's employment or earnings, then women's greater ability to provide for their families may grant them more decision-making power within the home, including decisions about delivering in hospitals and other formal healthcare centers as opposed to in one's home, should improve postnatal health by reducing the risk of postpartum infection, and providing skilled birth attendants who are equipped to address complications during delivery [21].

Education enhances health-seeking behaviors, and this may lead to the prevention and early detection of complications during pregnancy and childbirth and reduce the risk of death when complications arise but few studies have been able to determine whether women's education has a causal effect or whether the link between education and maternal health [21].

Financial capability directly affect whether women can actually reach a facility for delivery. The anticipation of high costs will affect whether a decision for a facility delivery is made in the first place. Women who are working and earning money may be able to save and decide to spend it on a facility delivery. However, in many settings, women either do not earn money for their work or do not control what they earn. On the other hand, working may be poverty induced and indicate recourse constraints which would make working mother less likely to use health service for delivery [22]. For example, in two southern Indian States and in Nepal, working women, may signify that working is poverty induced [23]. A study also found an interesting interaction that favor employed women gainfully among those living more than one hour travel time from a health centre, while employment status does not play a role among those within one hour travel time, and this could be due to employed women being better equipped to overcome access barrier including transportation costs or female mobility limitation [22].

Therefore, this study is aimed to explore the significance of the influence of some socio-economic factors on choices of childbirth places among women in Oyigbo local government area of Rivers State, Nigeria and the significance of the influence of income and educational status on choices of childbirth places among women in Oyigbo local government area of Rivers State, Nigeria. 


\section{Methodology}

This chapter discusses the strategies and framework of the study as follows: Research Design, background of the sampling population, sample size, sample and sampling technique, instrumentation, reliability and validity of instrument, data collection procedure and the methods of data analysis.

\subsection{Research Design}

The researcher deployed a qualitative type of design which is descriptive and a cross-sectional research study approach which involves collecting, analyzing and interpreting data collected through questionnaire.

\subsection{Study Area}

Oyigbo Local government is one of the 23 local governments of Rivers State of the South-South geopolitical zone of Nigeria. It's headquarter is in a town known as Afam. The local government is about 30 kilometers away from Port Harcourt, the capital city of Rivers State, with an estimated population of about 209,841 [24]. The area hosts members of the Oyigbo sub-division of the Igbo ethnic group. The Obigbo dialect is the language commonly spoken in the local government. The practice of Christianity and traditionalism dominates the towns within the local government with Aanang language also spoken in the area. Because of the closeness to Aba, a popular Igbo town in Abia state, Oyigbo also has some part dominated by Igbos. The traditional ruler in the local government is known as the Eze of Oyigbo. There are notable festivals held in the area with the most popular one as the Ekpe masquerade festival [24].

Oyigbo is made up of towns, villages and districts such as Umuosi, Okoloma, Azusogu, Ndoki and Okponta. The average temperature of the environment is about $25^{\circ} \mathrm{C}$ with the environment being surrounded by several rivers and their tributaries. The average wind speed is recorded at $12 \mathrm{~km} / \mathrm{h}$ and the environment is known for its rich deposits of crude oil. The crude oil deposits have led to the establishment of various Energy, oil and gas companies in the area, such as the Shell Petroleum Company.

Also, the establishments of other mining corporations all contribute to the economy of the area. Oyigbo Local government is also a fishing site for commercial fishermen due to the presence of the surrounding rivers. Other economic activities that take place in the area include trade and farming [24]. The proximity to the popular market in Aba in Abia State has ensured that business activities in the Oyigbo have improved. Most people go to the more creative markets in Aba to get the commodities which they sell for profit to the residents of Oyigbo and Port Harcourt.

\subsection{Study Population}

The study population was women in Oyigbo Local Government Area, this included both women of childbearing age who are resident in the area of the study and women who failed or refused to give 
consent because they were morbidly ill and afraid of losing their privacy. Women of childbearing age were randomly selected to participate but only 384 responded in the study.

\subsection{Sample and Sampling Technique}

The sample was randomly selected from women of child bearing age, who are indigenes and also resident in Oyigbo Local Government area in Rivers State. The sampling method employed was the simple random sampling.

According to Charan and Biswas (2013), the sample size was determined using the Fischer's formula: $\mathbf{n}=$ $\left(Z^{2} \times \mathbf{p} \times \mathbf{q}\right) / \mathbf{d}^{2}$ with $\mathbf{n}$ as the sample size $Z$ is the normal variable associated with significance level a (1.96 is the normal deviate associated with $95 \%$ confidence interval); $\mathbf{p}$ is Proportion of the population with the desired characteristic; $\mathbf{q}=1-p ; \mathbf{d}$ is the required level of precision/discrepancy $=5 \%$; [25]

Sample size was calculated as 384

$1.96^{2} \times 0.5 \times(1-0.5)$

$0.05^{2}$

$=384$

2.5 Sources of Data

In this study, statistical source of data was implored through sample survey from the community leaders and women of child bearing age.

\subsection{Method of Data Collection}

Data were collected primarily from the respondents through the formal administration of questionnaire. The instrument was administered in person by the researcher to 384 women of child bearing age in Oyigbo Local Government area. The service of a research assistant was used to collate and assemble the instrument.

\section{Questionnaire}

research subjects were given multiple choice questions to answer, this was subdivided into three sections namely; Socio-economic characteristics/Bio-data, Common childbirth places, and Social factors influencing choice of childbirth places.

For the unlearned women the questionnaire was interpreted into local languages and they were helped recording their response.

\subsection{Reliability and Validity of Instrument}


The reliability of the instrument was determined through the test retest method. To ascertain the reliability co-efficient, 10 copies of the instrument were administered to a sample of 10 randomly selected women of childbearing age in Oyigbo Local Government Area of Rivers State, to respond to the items presented and the instruments were retrieved for analysis.

The same copy of instrument was given to the same sample after two weeks of the initial one. The initial and final analysis was correlated and the reliability co-efficient was 0.81 . To ensure further validity of the instrument, it was given to the research supervisor for corrections and proper adjustments.

\subsection{Method of Data Analysis}

Data was analyzed using the Statistical Package for Social Sciences (SPSS) Version 22 (SPSS Inc., Chicago, IL., USA). Results of research question one to three were presented as frequency tables and percentage, and the hypotheses used to test the association was carried out using Chi-square, with level of significance set as $p<0.05$.

\subsection{Ethics Approval}

All information was handled with uttermost confidentiality. Privacy was implemented in line with Data privacy policy and protection. the research subjects reserve the right to privacy of non-disclosure of their details. A written informed consent was obtained from the subjects. The research received ethical approval from research ethics committee of university of Port Harcourt office of research management and development UPH/CEREMAD/REC/MM68/025 on 20th December 2019. And acceptance and permission for research in OYIGBO by the HRH Eze Mike Nwaji JP on 22nd April 2020.

\section{Result}

\subsection{Analysis of Demographic Data}


Table 1

Socio-demographic Characteristics of the Respondents

\begin{tabular}{|c|c|c|}
\hline Demography & Frequency $(n=384)$ & Percent \\
\hline \multicolumn{3}{|l|}{ Age } \\
\hline $20-25 y r s$ & 65 & 16.9 \\
\hline 26-31yrs & 198 & 51.6 \\
\hline 32-37yrs & 99 & 25.8 \\
\hline 45yrs \& above & 22 & 5.7 \\
\hline \multicolumn{3}{|l|}{ Educational Level } \\
\hline No Formal Education & 22 & 5.7 \\
\hline Primary Education & 11 & 2.9 \\
\hline Secondary Education & 219 & 57.1 \\
\hline Tertiary Education & 110 & 28.6 \\
\hline Post-Graduate Education & 22 & 5.7 \\
\hline \multicolumn{3}{|l|}{ Marital Status } \\
\hline Married & 351 & 91.4 \\
\hline Single & 22 & 5.7 \\
\hline Separated & 11 & 2.9 \\
\hline \multicolumn{3}{|l|}{ Income } \\
\hline$<\# 30,000$ & 263 & 68.5 \\
\hline \#30,000-\#79,999 & 66 & 17.2 \\
\hline \#80,000-\#149,999 & 22 & 5.7 \\
\hline \#150,000-\#349,999 & 22 & 5.7 \\
\hline \#350,000 \& above & 11 & 2.9 \\
\hline \multicolumn{3}{|l|}{ Occupation } \\
\hline Public Civil Servants & 33 & 8.6 \\
\hline Private Civil Servants & 77 & 20.1 \\
\hline Business/Traders & 230 & 59.9 \\
\hline Others & 44 & 11.4 \\
\hline
\end{tabular}


From the socio-demographic characteristics of age of the women of child-bearing age in Oyigbo, (65) respondents representing $16.9 \%$ are $20-25 \mathrm{yrs}, 198$ respondents representing $51.6 \%$ are $26-31 \mathrm{yrs}, 99$ respondents representing $25.8 \%$ are $32-37 y r s, 22$ respondents representing $5.7 \%$ are $45 y$ rs and above. On the educational level of the respondents, 22 respondents representing $5.7 \%$ had no formal education, 11 respondents representing $2.9 \%$ had primary education, 219 respondents representing $57.1 \%$ had secondary education, and 110 respondents representing $28.6 \%$ had tertiary education while 22 respondents representing $5.7 \%$ had post-graduate education. On the marital status of the respondents, 351 respondents representing $91.4 \%$ are married, 22 respondents representing $5.7 \%$ are single while 11 respondents representing $2.9 \%$ are separated. On the income of the respondents, 263 respondents representing $68.5 \%$ earn less than $\# 30,000 ; 66$ respondents representing $17.2 \%$ earn $\$ 30,000-79,999$; 22 respondents representing $5.7 \%$ earn $\$ 80,000$ 149,999; also, 22 respondents representing $5.7 \%$ earn \#150,000-\#349,999 while 11 respondents representing 2.9\% earn \#350,000 \& above income. On the occupation of the respondents, 230 respondents representing $59.9 \%$ are businessmen/traders; 77 respondents representing $20.1 \%$ are private civil servants; 44 respondents representing 11.4 are for others while 33 respondents representing $8.6 \%$ are public civil servants.

\subsection{Common choices of childbirth places among the women in Oyigbo}

Table 2

Choice of childbirth place among the women of childbearing age

\begin{tabular}{|lllll|}
\hline CHILDBIRTH PLACE & YES & \multicolumn{3}{l|}{ NO } \\
\cline { 2 - 5 } & Frequency & Percent \% & Frequency & Percent \% \\
\hline Hospital/Health Facility & 351 & 91.4 & 33 & 8.6 \\
\hline Traditional Birth Attendant Homes & 19 & 4.9 & 365 & 95.1 \\
\hline Home delivery & 9 & 2.3 & 375 & 97.7 \\
\hline Others & 5 & 1.3 & 379 & 98.7 \\
\hline YES: represents number of respondents that chose the childbirth place. \\
\hline
\end{tabular}

NO: represents number of respondents that did not choose the childbirth place.

Table 2 shows choice of childbirth place among the women of childbearing age in Oyigbo. The result revealed that 351 respondents representing $91.4 \%$ choose hospital/health facility, 19 respondents representing $4.9 \%$ choose traditional birth attendant homes, 9 respondents representing $2.3 \%$ choose home delivery while 5 respondents representing $1.3 \%$ choose others as their choice of childbirth place in Oyigbo Local Government Area of Rivers State.

\subsection{Social factors influencing choice of childbirth place among the women in Oyigbo}


Table 3 shows the social factors affecting the choices of childbirth place of the women in Oyigbo. The result revealed that 165 respondents representing $42.97 \%$ indicated that road access to health facility affected their choice, 99 respondents representing $25.78 \%$ indicated the distance of health facility affected their choice, 199 respondents representing $51.82 \%$ indicated the available finance affected their choice, and 144 respondents representing $37.5 \%$ indicated that the unavailability of skilled birth personnel in a birthing place affected their choice.

Table 3

Social factors affecting the women's choice of childbirth places in Oyigbo L.G.A

\begin{tabular}{|lllll|}
\hline SOCIAL FACTORS & YES & \multicolumn{3}{l|}{ NO } \\
\cline { 2 - 5 } & Frequency & Percent \% & Frequency & Percent \% \\
\hline Road access to health facility & 165 & 42.97 & 219 & 57.03 \\
\hline Distance from health facility & 99 & 25.78 & 285 & 74.22 \\
\hline Available finance & 199 & 51.82 & 185 & 48.18 \\
\hline Unavailability of skilled birth personnel & 144 & 37.5 & 240 & 62.5 \\
\hline YES: respondents affected by factor. NO: respondents not affected by factor. & \\
\hline
\end{tabular}

\subsection{Significance of the influence of social factors on the women's choices of childbirth places}

Table 4 shows the chi-square contingency table of social factors and childbirth place, this consists of the observed count and the expected count revealing the way the variables are distributed into categories. The null and the alternate hypothesis as stated below;

$\mathrm{H}=$ There is no significant association between social factors and choices of childbirth places among the women

$\mathrm{H}=$ There is significant association between social factors and choices of childbirth places among the women 
Table 4

Extent to which social factors affect the women's choice of childbirth places

\begin{tabular}{|llllll|}
\hline & \multicolumn{5}{c}{ CHILDBIRTH PLACE } \\
\cline { 2 - 6 } & & HOSPITAL & TBA & HOME & OTHERS \\
\hline \multirow{2}{*}{ SOCIAL FACTORS } & YES & 295 & 15 & 9 & 4 \\
\cline { 2 - 6 } & NO & 332 & 19 & 9 & 5 \\
\hline
\end{tabular}

Pearson Chi-Square Tests

\begin{tabular}{|lll}
\hline \multirow{3}{*}{ SOCIAL FACTORS } & & CHILDBIRTH PLACE \\
\cline { 2 - 3 } & Chi-square & 4.661 \\
\cline { 2 - 3 } & Df & 8 \\
\cline { 2 - 3 } & Sig. & 0.793 \\
\hline
\end{tabular}

The table revealed that the $x^{2}$ cal is 4.661 with $\mathrm{df}=8$ and $p>0.05$. The obtained $p$-value of 0.793 is greater than the level of significance 0.05 , therefore, the null hypothesis is accepted and alternate hypothesis is rejected. This indicates no significant association between social factors and choice of childbirth places. This is to say that the way social factors are distributed into categories does not change at different level of childbirth choices among the women of childbearing age in Oyigbo Local Government Area of Rivers State.

\subsection{Significance of the educational status on the women's choices of childbirth places in Oyigbo}

Table 5 revealed a great difference in observed and expected count between the variables. This implies that the way the variables are distributed into categories changed. The null and the alternate hypothesis are as stated below;

$\mathrm{H}=$ There is no significant association between educational qualification and choices of childbirth places among the women

$\mathrm{H}=$ There is significant association between educational qualification and choices of childbirth places among the women. 
Table 5

Association between the educational qualifications and choice of childbirth place

\begin{tabular}{|llllll|}
\hline \multirow{2}{*}{ EDUCATION } & & \multicolumn{4}{l|}{ CHILDBIRTH PLACE } \\
\cline { 2 - 6 } & HOSPITAL & TBA & HOME & OTHERS \\
\cline { 2 - 6 } & NONE & 22 & 2 & 2 & 0 \\
\cline { 2 - 6 } & PRIMARY & 11 & 0 & 0 & 0 \\
\cline { 2 - 6 } & SECONDARY & 197 & 17 & 6 & 5 \\
\cline { 2 - 6 } & TERTIARY & 99 & 0 & 1 & 0 \\
\hline & POSTGRADUATE & 22 & 0 & 0 & 0 \\
\hline
\end{tabular}

Pearson Chi-Square Tests

CHILDBIRTH PLACE

\begin{tabular}{lll} 
EDUCATION & Chi-square & 23.257 \\
\cline { 2 - 3 } & Df & 16 \\
\cline { 2 - 2 } & Sig. & 0.107 \\
\hline
\end{tabular}

This results to a large magnitude in $x^{2}$ cal as 23.257 with $d f=16$ and $p>0.05$. The obtained $p$-value of 0.107 is greater than the level of significance 0.05 . Therefore the null hypothesis that there is no significant association between the educational qualifications and childbirth places among the women in Oyigbo Local Government Area of Rivers State is accepted.

\subsection{Significance of the levels of income on the women's choices of childbirth place in Oyigbo}

Table 6 showed the observed count and the expected count revealing the way the variables are distributed into categories. The null and the alternate hypothesis as stated below;

$\mathrm{H}=$ There is no significant association between income levels and choices of childbirth places among the women

$\mathrm{H}=$ There is significant association between income levels and choices of childbirth places among the women 
Table 6

Association between the levels of income and choice of birth place

\begin{tabular}{|llllll|}
\hline \multirow{5}{*}{ INCOME } & \multicolumn{4}{l}{ CHILDBIRTH PLACE } \\
\cline { 2 - 6 } & HOSPITAL & TBA & HOME & OTHERS \\
\cline { 2 - 6 } & LESS THAN \#30,000 & 252 & 16 & 7 & 3 \\
\cline { 2 - 6 }$\# 30,000-\# 79,999$ & 66 & 3 & 2 & 0 \\
\cline { 2 - 6 }$\# 80,000-\# 149,999$ & 11 & 0 & 0 & 2 \\
\hline$\# 150,000-\# 349,999$ & 22 & 0 & 0 & 0 \\
\hline$>\# 350,000$ & 0 & 0 & 0 & 0 \\
\hline
\end{tabular}

Pearson Chi-Square Tests

CHILDBIRTH PLACE

INCOME Chi-square $\quad 75.701$

Df 12

Sig. $\quad 0.000$

The $x^{2}$ cal is 75.701 with $d f=12$ and $p<0.05$. The obtained $p$-value of 0.000 is less than 0.05 . Therefore the null hypothesis is rejected. This indicates that there is a significant association between the levels of income and childbirth places among the women of childbearing age in Oyigbo Local Government Area of Rivers State.

\section{Discussion}

\subsection{Choice of childbirth place among the women of childbearing age}

From the findings of the study as revealed in Table 2, 91.4\% of the respondents (majority of the respondents) choose hospital/health facility as childbirth place than traditional birth attendant homes, home delivery and others. This implies that the respondents are aware of the presence of skilled medical professionals in hospitals/ health centres which is the assurance of their safe delivery [26]. This suggests that the women of childbearing age in Oyigbo are mostly educated, which agrees with Okeshola and Sadiq in their study that in terms of educational background, most educated women prefer hospital child delivery to home delivery [22]. Other studies like Nigeria Demographic and Health Survey (NDHS) may have divergent opinion that majority of women of child bearing age, deliver at home [27]. But unlike the northern part of Nigeria which has the highest number of records of such births [11], the southern part of Nigeria is lower. 


\subsection{Social factors and choice of childbirth place among the women of childbearing age}

Findings from Table 4 revealed that there is no significant association between social factors and choice of childbirth place among the women of childbearing age in Oyigbo Local Government Area of Rivers State, contradicting Omideyi (2008) who pointed out that social factors affect the choice of childbirth places among women of child bearing age in most countries of Africa [10], and Esienumoh et al. (2016) study which is in disagreement to our result noted that the residents of riverine areas of Bayelsa and some parts of Rivers state have adopted home births as their lifestyle because it is easier to deliver at home than cross the river on a boat during labor to a nearby hospital in such environments [15]. However, due to the emerging urbanization in Oyigbo local government area, there are more health facilities closer to these women with navigable access roads therefore social factor seem not to have significant effect on the women's choices of childbirth place.

\subsection{Educational qualification and choice of childbirth place among the women of childbearing age}

Findings from Table 5 revealed that there is no significant association between the educational qualifications and choice of childbirth place among the women of childbearing age in Oyigbo Local Government Area of Rivers State. Weighing the impact of the level of education among the women; albeit majority of the respondents had secondary and tertiary education, most of the women from all levels of education chose hospital delivery. The importance of education is an essence of antenatal care and how to manage disease/illness experienced by pregnant women [1] which they get from the hospitals/health facilities. This opposes Weitzman (2017) avowal on the importance of education on maternal practices and healthcare use, stating that the effect of education predominantly flow through women's cognitive skills, material resources, and autonomy [21]. Omideyi (2007) who pointed out that, social factors such as level of education affect the choice of childbirth places among women of child bearing age in most countries of Africa [10].

\subsection{Level of income and choice of childbirth place among the women of childbearing age}

Findings from Table 6 revealed that there is a significant association between the level of income and choice of childbirth place among the women of childbearing age in Oyigbo Local Government Area of Rivers State. According to Ronsmans and Graham, economic accessibility to medical care affects the child birth practices of women in sub-Saharan Africa [9]. Income level could influence the way an individual thinks, his lifestyle and attitude. This study concurs to Okeshola and Sadiq which articulates that Unemployed women who their husbands cannot afford to cover the cost implication of delivery at hospitals usually encourage their wives to either deliver at home or in an unskilled birth attendants place, and for most mothers who are neither restricted by finance, it is the safety of mothers and their babies that determines place of delivery [22]. Again, the individuals' residence and personal lifestyle which are 
determined by their level of income is affected. This was noted by WHO in their study that maternal mortality has become a serious problem in middle income countries with Sub-Saharan African amounting for $56 \%$ of the maternal deaths [2].

Related to this are the financial capabilities of the women; when they earn low, they cannot meet up with the cost of receiving medical care and professional services in the environment. Women who are working and earning money may be able to save and decide to spend it on a facility delivery of their choice.

\section{Conclusion}

Based on the findings of the study, there has been a high level of hospital/health facility adherence among the women of childbearing age in Oyigbo Local Government Area of Rivers State, this could be attributed to the improved living standards of the society, urbanization in the area and most social hindrances have been curtailed with growing infrastructures. All in all, the social factors presented in this study, show a slight influence on the choices of childbirth places of women in Oyigbo Local Government Area of Rivers State.

Educational qualification among the women does not significantly affect their childbirth place choices. This could be attributed to easy accessibility of maternal health and antenatal knowledge to everyone even without formal education.

The levels of income influence significantly their choice of childbirth place, therefore, the cost implication of delivery in health facility and economic empowerment of women should be considered. More nonprofit health facility should be encouraged.

Therefore, this study has shown that the choice of childbirth place is majorly influenced by their level of income than educational status.

\section{Abbreviations}

i. WHO - World Health Organization

ii. NDHS - Nigeria Demographic and health survey

iii. SPSS - statistical Package for Social Science

iv. yrs - years

v. H - Null Hypotheses

vi. $\mathrm{H}$ - Alternative Hypotheses

vii. $d f$ - degree of freedom

viii. Sig. - level of statistical Significance (p-value)

ix. ${ }^{2}$ - chi-square

x. $p-p$-value 


\section{Declarations}

Ethics approval and consent to participate: A written informed consent was obtained from participants. The research received ethical approval from research ethics committee of university of port harcourt office of research management and development UPH/CEREMAD/REC/MM68/025 on 20th December 2019. And acceptance and permission for research in Oyigbo by the HRH Eze Mike Nwaji JP on 22nd april 2020.

Consent for publication: Not applicable.

Availability of data and materials: All data generated or analyzed during this study are included in this published article (and its supplementary information files).

Competing interests: The authors declare that they have no competing interests.

Funding statement: This study received no specific financial support.

Authors contribution: All authors contributed equally to the research.

Acknowledgments: We thank god and the entire crew of st. Paul's catholic church health post for their assistance and for giving us a platform for this research. Also gratefully thank obika f.c. For proofreading and cleaning.

\section{References}

1. Olonade, O, Olawande, TI, Alabi, OJ, \& Imhonopi, D. Maternal Mortality and Maternal Health Care in Nigeria: Implications for Socio-Economic Development. Open Access Maced. J. Med. Sci.. 2019;7(5):849-855. Doi: 10.3889/oamjms.2019.041

2. World Health Organization. Fact sheets.. Maternal mortality. WHO. Geneva 2019. https://www.who.int/news-room/fact-sheets/detail/maternal-mortality. Accessed 17 July 2020.

3. Kyei-Nimakoh M, Carolan-Olah M and Terence V. McCann. Millennium development Goal 5: progress and challenges in reducing maternal deaths in Ghana. BMC Pregnancy Childbirth. 2016;16:5. DOI: $10.1186 / \mathrm{s} 12884-016-0840-0$

4. Koblinsky, M, Chowdhury, ME, Moran, A, \& Ronsmans, C. Maternal morbidity and disability and their consequences: neglected agenda in maternal health. J Health Popul Nutr. 2012;30(2), 124-130. Doi: 10.3329/jhpn.v30i2.11294

5. Filippi V, Chou D, Ronsmans C, Graham W, and Say L. Levels and Causes of Maternal Mortality and Morbidity. In: Black RE, Laxminarayan R, Temmerman M, et al., editors. Reproductive, Maternal, Newborn, and Child Health: Disease Control Priorities. 3rd ed (2). The International Bank for Reconstruction and Development / The World Bank. Washington (DC). 2016;Ch3. Accessed from: https://www.ncbi.nlm.nih.gov/books/NBK361917/ doi: 10.1596/978-1-4648-0348-2_ch3 
6. Aluko-Arowolo SO and Ademiluyi,I. A. Understanding Maternal Health in the Context of culture, Infrastructure and Development in Pluralististic Nigerian Society. Int. J. humanit. soc. sci.. 2015;5(4):151-158.

7. Cockrill, K and Nack A. I'm Not That Type of Person': Managing the Stigma of Having an Abortion. Deviant Behav. 2013;34 (12): 973-90.

8. World Health Organization. Maternal mortality: WHO fact sheet on maternal mortality with key facts and providing information on MDG 4, where deaths occur, causes, lack of care and WHO response. WHO. Geneva. 2018.

9. Ronsmans $C$ and Graham WJ. Maternal mortality: who, when, where, and why. The Lancet. 2006;368(9542):1189-200. Retrieved 28 November 2019 from: <backgroundcolor:\#FF3300;uvertical-align:super;>https://www.thelancet.com/journals/lancet/a</backgroundcolor:\#FF3300;uvertical-align:super;>

10. Omideyi, AK. Poverty and development in Nigeria: trailing the MDGs?. Afr. J. Infect. Dis.. 2007;1(1): 3-17. Doi: 10.4314/ajid.v1i1.42088.

11. Bukar M, Jauro YS. Home births and postnatal practices in madagali, North-Eastern Nigeria. Niger J Clin Pract. 2013;16:232-7.

12. Ezeama, MC and Ezeamah, I. Attitude and socio-cultural practice during pregnancy among women in Akinyele L. G. A. of Oyo State, Nigeria. J. Res. Nurs. Midwifery. 2014; 3(1):14-20

13. Aleni, M, Mbalinda, SN and Muhindo, R. Birth Intervals and Associated Factors among Women Attending Young Child Clinic in Yumbe Hospital, Uganda. Int. J. Reprod. Med 2020;1326596. https://doi.org/10.1155/2020/1326596

14. Ajiboye, OE and Adebayo, KA. Socio-cultural factors affecting pregnancy outcome among the Ogu speaking people of Badagry area of Lagos State, Nigeria. Int. j. humanit. soc. sci. 2012;2(4), 133144.

15. Esienumoh, EE, Akpabio, II, Etowa, JB and Waterman, H. Cultural Diversity in Childbirth Practices in a Rural Community in Southern Nigeria. J Preg Child Health. 2016;3: 280. doi:10.4172/2376$127 X .1000280$

16. Egharevba, J, Pharr, JR, Wyk, VB and Ezeanolue, E E. Factors influencing the choice of child delivery location among women attending antenatal care services and im- munization clinic in Southeastern Nigeria. Int J MCH AIDS. 2017;6(1), 82-92.

17. World Health Organization. Antenatal care in developing countries: promises, achievements and opportunities: an analysis of trends, levels and differentials, Department of Reproductive Health and Research. WHO. Geneva, Switzerland. 2015

18. Nayak MG, Sharada, George A. Socio-cultural perspectives on Health and Illness. NUJHS. 2012;2(3): 61-67

19. Liyew EF, Yalew AW, Afework MF, Essén B. Incidence and causes of maternal near-miss in selected hospitals of Addis Ababa, Ethiopia. PLoS ONE. 2017;12(6): e0179013.

doi:10.1371/journal.pone.0179013

Page 18/19 
20. Graham, WJ, Bell, JS and Bullough, CHW. Can skilled attendance at delivery reduce maternal mortality in developing countries? In: De Brouwere,V, Van Lerberghe,W, editors. Safe Motherhood Strategies: A Review of the Evidence. Studies in Health Services Organisation and Policy. 2001.

21. Weitzman A. The effects of women's education on maternal health: Evidence from Peru. Soc Sci Med. 2017;180:1-9. doi:10.1016/j.socscimed.2017.03.004.

22. Okeshola, F.B., \& Sadiq, I. Determinants of Home Delivery among Hausa in Kaduna South Local Government Area of Kaduna State, Nigeria. Am. Int. J. Contemp. 2013; 3: 5.

23. Sharma S., Smith S., Sonnavelett E., Pine M., Dayaratna V., Sanders R. Formal and Informal Fees for Maternal Health Care Services in Five Countries: Policies and Perspectives. PolicyWorking Paper Series No.16, USAID, June 2005.

24. Nwaji PO. "Peaceful Oyigbo". The Port Harcourt Telegraph. 2009. http://www.thephctelegraph.com/stories/July\%202009/2207news_07.html. Accessed 2 January 2020.

25. Charan, J., \& Biswas, T. How to calculate sample size for different study designs in medical research?. Indian J. Psychol. Med. 2013;35(2), 121-126. <background-color:\#CFBFB1; uverticalalign:super;>https://doi.org/10.4103/0253-7176.116232</background-color:\#CFBFB1;uverticalalign:super;>

26. Ugwu, N. U. and de Kok, B. (). Socio-cultural factors, gender roles and religious ideologies contributing to Caesarian-section refusal in Nigeria. Reprod. Health 2015;12:70 DOI 10.1186/s12978015-0050-7

27. Nigeria Demographic and Health Survey (NDHS). Preliminary Report. National Population Commission. Federal Republic of Nigeria, Abuja. 2018.

\section{Supplementary Files}

This is a list of supplementary files associated with this preprint. Click to download.

- suplimentaryDocument.docx 